\title{
Alcoholism, Korsakoff's Syndrome and the Frontal Lobes
}

\author{
R. R. JACOBSON \\ St. George's Hospital Medical School, Department of Psychiatry, Jenner Wing, Cranmer Terrace, \\ Tooting, London, SW17 ORE
}

\begin{abstract}
A subset of the diffuse cerebral changes and psychometric deficits found in chronic alcoholics is similar to that seen in the frontal lobe syndrome. Certain features of alcoholic Korsakoff's syndrome (AKS) also point to cortical involvement, and this may have a basis in alcohol neurotoxicity.

Twenty-five patients with AKS and 24 non-Korsakoff alcoholic controls were compared using an automated CT brain scan program. In addition to evidence of their diencephalic lesions (wide third ventricles), AKS patients revealed widespread cerebral damage with greater Sylvian and interhemispheric fissure (IHF) size than alcoholics. Korsakoffs were also inferior to alcoholics in performance on a category sorting test, in which non-perseverative error scores correlated significantly with IHF size.

The principle of distinguishing between selective memory decline and global intellectual decline (GID) was applied to 38 patients with AKS. Indices were developed for each type of deficit and much variation found in their distributions. The degree of GID correlated significantly with IHF size, showing similar trends with other cortical measures.

These results suggest a cortical substrate for the degree of GID and a frontal substrate for category sorting deficits; with a probable basis in alcohol neurotoxicity rather than thiamine deficiency, which is not known to impair cortical structure. A new model is proposed of the pathophysiology of alcoholic brain damage and AKS which includes recent work on neurotransmitter sources and thalamo-frontal connections.
\end{abstract}

\section{Introduction}

The frontal lobes have been at the centre of debate and controversy concerning cognitive processing and the regulation of complex behaviour in humans, brain evolution and the mind--body problem. Current research has highlighted the normal and the abnormal neurobiology and psychology of the frontal lobes. I shall discuss two disorders, chronic alcoholism and alcoholic Korsakoff's syndrome, from the perspective of the frontal lobes.

Alcoholics reveal symptoms, psychometric deficits and neuropathology which implicate widespread structural and functional changes (Ron, 1983). A subset of these features is similar to that seen in the frontal lobe syndrome (FLS). I shall argue that if the alcoholic has frontal features, then so does the patient with alcoholic Korsakoff's syndrome (AKS); and that frontal abnormalities may be necessary, although insufficient, for full expression of AKS. 


\section{Frontal lobe symptoms in alcoholism}

Several clinical symptoms seen in alcoholism are similar to those found in patients with focal frontal lesions. In 1879, Maudsley described weak willpower and deterioration of memory, moral sense and understanding in patients with alcoholic dementia. Sir Aubrey Lewis (1952) wrote of "deficiencies of memory and judgement, laziness, indifference, facile euphoria and lability of mood with failure to observe responsibilities, mendacity, gross lack of self-control and general demoralization." In Horvath's (1975) series of 100 deteriorated alcoholics, behavioural abnormalities, apathy, emotional lability, perseveration and lack of insight were common features. Many of these symptoms are present in mild form in the clinically unimpaired alcoholic (Parsons, 1987).

\section{"Frontal" cognitive deficits in alcoholics}

Alcoholics are well-known to perform more poorly than controls on many tests of problem solving and abstracting abilities including the Halstead category and the Wisconsin card sorting tests (WCST). Impairments have been recorded across the different stages of performing abstracting tasks, including the formation of hypotheses, cognitive set persistence, utilization of feedback information contained in both correct and incorrect responses to monitor on-going problem solving, and flexibility in shifting to a new strategy when the current concept is no longer correct (Tarter, 1973; Acker et al., 1984; Tarter and Edwards, 1986). In reviewing the neuro-psychological evidence, Tarter and Edwards (1986) concluded that the impairments of alcoholics were very similar to those found in patients with anterior-basal brain lesions.

\section{CT brain scan studies in alcoholics}

CT brain scan studies have uniformly revealed a high incidence of cortical shrinkage and ventricular dilatation in large and relatively unselected populations of neurologically intact chronic alcoholics (Ron, 1983; Wilkinson, 1982).

Despite considerable variation between studies, the findings are largely consistent, accord with recent morphological reports and thereby indicate that a robust phenomenon has been described. The CT evidence suggests that about half to two-thirds of alcoholics develop atrophy often from quite early on in their alcoholic careers, and that the severity of structural change increases with age and is worse in the female alcoholic (Lishman et al., 1987). Cortical atrophy was found to be most prominent in frontal regions in only 2 out of over 10 studies (Cala et al., 1978; Von Gall et al., 1978). The success of CT scan studies in demonstrating brain shrinkage in alcoholics has prompted re-examination by neuropathologists who had previously been discordant on the issue (Lishman, 1981). 


\section{Morphometric studies in alcoholics}

Recent autopsy studies confirm the validity of the CT scan findings and particularly implicate the frontal regions. Brain weights were found to be significantly reduced in large numbers of male alcoholics compared to controls (Torvik et al., 1982; Harper et al., 1985). A quantitative estimate of the pericerebral space revealed brain shrinkage $70 \%$ greater in alcoholics than controls, and a selective reduction was found in the volume of cerebral white compared with cortical grey matter (Harper et al., 1985). In the first quantitative study of cortical neurones in alcoholics, Harper et al. (1987) reported that the number of cortical neurones in the superior frontal cortex was significantly reduced in chronic alcoholics compared to controls, whereas counts were equivalent in the motor cortex. Neuronal size was significantly smaller in both areas. Similar findings applied to alcoholics with Wernicke's encephalopathy and those with cirrhosis.

\section{Korsakoff's syndrome}

Given that there are the symptoms and psychological deficits of impaired frontal function and diminished neuronal counts in the superior frontal region in the clinically unimpaired alcoholic, could these changes contribute to AKS?

There are several reasons why chronic alcohol neurotoxicity may be a necessary, albeit insufficient, cause of KS. First, the possibility that thiamine deficiency causes Wernicke's encephalopathy and the addition of chronic alcoholism is necessary for Korsakoff's syndrome to appear in the same patient was raised by Freund (1973), who observed that a permanent amnesic syndrome had never been recorded in a patient with Wernicke's encephalopathy secondary to a cause other than alcoholism. This was borne out in de Wardener and Lennox's (1947) study of Far East prisoners of war, whose amnesia, when present, recovered promptly with thiamine treatment.

Secondly, certain clinical features of Korsakoff's syndrome may indicate cortical involvement, perhaps particularly frontal involvement. Apathy, lack of spontaneity and initiative, loss of insight, perseveration and impairment of planning are found in AKS and frontal lobe disorders (Talland, 1965; Zangwill, 1966; Luria, 1969; Stuss and Benson, 1986). The tendency to confabulate in an amnesic patient has been reported inversely to relate to performance on the WCST (Kapur and Coughlan, 1980). Zangwill (1966), in fact, emphasized that the pattern of psychological deficits in KS transcends uncomplicated amnesia, when he wrote: "Other and more extensive psychological dysfunction must co-exist with amnesia for the classic picture of Korsakoff's syndrome to emerge". Zangwill (1966) emphasized the striking deficiency of insight, to which Korsakoff (1889) himself drew attention. Although loss of insight may follow diencephalic lesions (Weinstein and Kahn, 1955), it is more typical of frontal disorders (Stuss and Benson, 1986).

Thirdly, alcoholic Korsakoff patients also perform poorly on tests 
sensitive to frontal function such as the WCST and verbal fluency tests (Squire, 1982; and vide infra).

Fourthly, special features of the memory disorder itself point specifically to frontal lobe involvement. These include increased susceptibility to interference, poor memory for temporal recency and order, difficulty in using imagery mnemonics, impaired self-ordered memory tasks and confabulation (see Moscovich, 1982, for discussion and references). Poor release from pro-active inhibition (PI) may also be included here because it has been related to low scores on three frontal tests in Korsakoff patientsWCST, word fluency and embedded figures tasks (Squire, 1982) - and is described in frontal patients by Moscovitch (1982). Source amnesia, the retrieval of experimentally presented information in the absence of a corresponding recollection of how it was acquired, occurs in AKS (Claparede, 1911) and has been reported in patients with frontal lesions when amnesia is present (Schachter et al., 1984). Most of these features of memory disorder are unrelated to the severity of anterograde amnesia (Squire, 1986), which has a near-zero correlation with extensive remote memory impairment in Korsakoff patients (Shimamura and Squire, 1986). The question arises whether extensive remote memory impairment is also caused by pathology additional to that required for anterograde amnesia, namely diencephalic lesions in the Wernicke location (Victor et al., 1971).

Several issues are raised, including the relative contributions of alcoholism and thiamine deficiency to AKS, and those of cortical disorder (due to alcoholism) and sub-cortical disorder (with a specific contribution from thiamine deficiency) to AKS. These issues are relevant to the confusion surrounding the term alcoholic dementia and its overlap with Korsakoff's syndrome which has been documented on neuropsychological (Cutting, 1978; Jacobson and Lishman, 1987) and neuropathological grounds (Harper, 1983; Torvik et al., 1982). At the Institute of Psychiatry these issues issues have been investigated by Prof. W. A. Lishman, Dr R. Jacobson and Mrs C. Acker using CT neuro-imaging and neuropsychological techniques.

\section{Cortical damage in Korsakoff patients}

Twenty-five male Korsakoff patients were selected with severe anterograde amnesia, retrograde amnesia, disorientation in time and place, lack of insight, and clinical grounds for regarding other cognitive functions as well preserved. They were scanned and compared with 24 age-matched nonKorsakoff chronic alcoholics. Patients with reason to suspect brain damage attributable to other causes were excluded. Measurements were made of lateral ventricular size, expressed as the ventricle brain ratio (VBR), and third ventricular width, which is expressed as an index. Sulcal and Sylvian fissure size were estimated by a visual grading procedure (Ron et al., 1982), and (frontal) interhemispheric fissure size (IHF) measured by automated pixel counts derived from a fully automated CT scan program (Baldy et al., 1986). 
TABLE 1. Comparison of age and CT scan indices in Korsakoffs and alcoholics

\begin{tabular}{lccc}
\hline & $\begin{array}{c}\text { Korsakoff } \\
\text { Patients } \\
(\mathcal{N}=25)\end{array}$ & $\begin{array}{c}\text { Non-Korsakoff } \\
\text { Alcoholics } \\
(\mathcal{N}=24)\end{array}$ & $\begin{array}{c}\text { Sig. by } \\
\text { t-test }\end{array}$ \\
\hline Mean age & $56 \cdot 1$ & $52 \cdot 6$ & $\mathrm{NS}$ \\
Third Ventricular Index & $5 \cdot 6$ & $4 \cdot 1$ & $\mathrm{xxx}$ \\
Lateral Ventricles (VBR) & $(2 \cdot 2)$ & $(1 \cdot 3)$ & $\mathrm{x}$ \\
Sulci enlarged & $13 \cdot 7$ & $10 \cdot 7$ & $\mathrm{NS}$ \\
Sylvian fissures enlarged & $(4 \cdot 9)$ & $(4 \cdot 6)$ & $\mathrm{x}$ \\
Interhemispheric fissure & $44 \%$ & $25 \%$ & $\mathrm{x}$ \\
Pixel counts & $68 \%$ & $29 \%$ & \\
\hline
\end{tabular}

Standard Deviation in brackets, $\mathrm{x} p<0.05, \operatorname{xxx} p<0.001$

Table 1 reveals that third ventricular widths are greater in the Korsakoff than the non-Korsakoff alcoholics, as might have been expected from their diencephalic lesions. Lateral ventricular size is, however, also significantly greater, and the Sylvian and inter-hemispheric fissures are wider.

It is concluded that in addition to their well-established diencephalic lesions, many Korsakoff patients have sustained widespread cerebral damage. Shrinkage in the frontal brain regions (reflected in interhemispheric fissure size) appears to be especially pronounced.

\section{"Frontal" psychometric performance}

Korsakoffs also reveal poor performance in the category sorting test, derived from Nelson's (1976) modification of the Wisconsin card sorting test and adapted for the microcomputer (Acker and Acker, 1982). Korsakoffs and controls had significantly different mean estimates of pre-morbid verbal intelligence as indicated by the National Adult Reading Test (NART) (Nelson and O'Connell, 1978). After out-partialling the NART IQ the two groups do not differ significantly on the block design tests whereas Korsakoffs reveal poor performance on both the category sorting test (CST) and a test of alternating verbal fluency, the number of pairs of alternating birds and colours produced in one minute - thought to be sensitive to frontal lobe function (Newcombe, 1969) (Table 2).

Compared to alcoholics, Korsakoffs also reveal impaired performance on both the category sorting and alternating verbal fluency tests (Table 3 ).

Are the frontal structural changes found in Korsakoffs related to poor performance on the category sorting and verbal fluency tests? We found that the frontal IHF size was significantly related to several scores on the CST, after controlling for the NART IQ and the duration abstinent. As IHF size increased, mean reaction times on the CST were slower $(p<0 \cdot 05)$, and 
TABLE 2. Comparison of Korsakoffs and controls on block design and "frontal" tests

\begin{tabular}{lcccc}
\hline & $\begin{array}{c}\text { Korsakoffs } \\
\text { Mean } \\
(\mathcal{N}=24)\end{array}$ & $\begin{array}{c}\text { Controls } \\
\text { Mean } \\
(\mathcal{N}=20)\end{array}$ & $\begin{array}{c}\mathcal{N} A R T \\
p\end{array}$ & $\begin{array}{c}\text { Group } \\
p\end{array}$ \\
\hline Block Design & $23 \cdot 3$ & $34 \cdot 9$ & $\mathbf{x x x}$ & $\mathrm{NS}$ \\
Category Sorting Test & & & & \\
$\quad$-Categories & $3 \cdot 4$ & $5 \cdot 2$ & $\mathbf{x x x}$ & $\mathrm{NS}$ \\
- Total sorts & $100 \cdot 7$ & $61 \cdot 2$ & $\mathbf{x x x}$ & $\mathbf{x x}$ \\
- Total errors & $55 \cdot 0$ & $22 \cdot 0$ & $\mathbf{x x x}$ & $\mathbf{x x}$ \\
- Persev. errors & $38 \cdot 1$ & $10 \cdot 6$ & $\mathbf{x x x}$ & $\mathbf{x x x}$ \\
-Consec. persev. errors & $21 \cdot 4$ & $5 \cdot 1$ & $\mathbf{x x x}$ & $\mathbf{x}$ \\
Verbal Fluency & & & & \\
Alternating birds/colours & $4 \cdot 5$ & $8 \cdot 7$ & $\mathbf{x x x}$ & $\mathbf{x x x}$ \\
\hline
\end{tabular}

$\mathrm{x} p<0.05, \mathrm{xx} p<0.01, \mathrm{xxx} p<0.001$

TABLE 3. Comparison of Korsakoffs and alcoholics on "frontal" tests

\begin{tabular}{lccc}
\hline & $\begin{array}{c}\text { Korsakoffs } \\
\text { Mean } \\
(\mathcal{N}=24)\end{array}$ & $\begin{array}{c}\text { Alcoholics } \\
\text { Mean } \\
(\mathcal{N}=24)\end{array}$ & $p$ \\
\cline { 1 - 3 } Category Sorting Test & & & \\
- Categories & $3 \cdot 4$ & $4 \cdot 7$ & $\mathbf{x}$ \\
- Total sorts $\quad 100 \cdot 7$ & $73 \cdot 6$ & $\mathbf{x x}$ \\
- Total errors & $55 \cdot 0$ & $31 \cdot 2$ & $\mathbf{x x}$ \\
- Perseverative errors & $38 \cdot 1$ & $18 \cdot 0$ & $\mathbf{x x}$ \\
Verbal Fluency & $21 \cdot 4$ & $9 \cdot 3$ & $\mathbf{x}$ \\
Alternating birds/colours & & & \\
\hline
\end{tabular}

$\mathrm{x} p<0.05, \mathrm{xx} p<0.01, \mathrm{xxx} p<0.001$

there were more errors after positive feedback $(p<0.05)$ and more irrational errors $(p<0.05)$; but no association emerged with perseverative errors. There was a trend to more total errors. Because multiple comparisons within a large data set can yield spuriously significant results, we performed a principal components analysis on the psychometric data. A concepts factor emerged with principal loadings on selective category sorting test measures - the number of sorts, total numbers of errors after positive feedback and irrational errors, and with negligible loadings on perseverative errors. Once again the IHF size correlated significantly with the concepts scale, after controlling for the NART IQ $(r=0.65, p<0.05)$, and this remained significant after further controlling for the duration of diagnosis. 
No association emerged between (frontal) IHF size and perseverative error scores in the CST; which is consistent with Milner's (1964) observation that perseverative errors in the WCST are related to lesions of the dorsolateral frontal cortex.

Therefore several features of Korsakoff amnesia which correlate significantly with CST scores are likely to depend, at least in part, on frontal dysfunction and frontal cortical atrophy. This association could of course be conditional on the presence of amnesia (Schachter et al., 1984) and receive a contribution from frontal deafferentation by diencephalic lesions (Bewermeyer et al., 1985).

How do the abstracting and verbal fluency deficits of Korsakoff patients compare with those resulting from lesion studies? Table 4 reveals that the main number of categories achieved by male Korsakoffs is equivalent to the means for Nelson's frontal lesion groups. Female Korsakoffs (vide infra) do worse. The mean percentage of consecutive perseverative to total errors is slightly less in male Korsakoffs than Nelson's lesion groups but equivalent in female Korsakoffs and the lesion groups. The alternating verbal fluency scores of Korsakoff patients are lower than the means for Newcombe's series of patients with focal brain damage following head injury. The equivalence of these frontal test results between Korsakoffs and lesion patients could be spurious because of differences in the type of lesion (diffuse versus focal), differences in pre-morbid intelligence and importantly differences in the degree of intellectual decline (Robinson et al., 1980). The fall in general intellectual competence from premorbid levels in Korsakoff patients is, in fact, an important, neglected issue.

TABLE 4. Comparison of Korsakoffs and patients with focal lesions on category sorting and verbal fluency tests

\begin{tabular}{|c|c|c|c|c|}
\hline & \multicolumn{2}{|c|}{ Korsakoffs } & \multicolumn{2}{|c|}{ Nelson (1976) } \\
\hline & $\begin{array}{c}\text { Male } \\
(\mathcal{N}=24) \\
\text { Mean } \\
\text { (S.D.) }\end{array}$ & $\begin{array}{c}\text { Female } \\
(\mathcal{N}=13) \\
\text { Mean } \\
\text { (S.D.) }\end{array}$ & $\begin{array}{c}\text { L. Frontal } \\
(\mathcal{N}=9) \\
\text { Mean } \\
\text { (S.D.) }\end{array}$ & $\begin{array}{c}\text { R. Frontal } \\
(\mathcal{N}=16) \\
\text { Mean } \\
\text { (S.D.) }\end{array}$ \\
\hline \multicolumn{5}{|l|}{ Category Sorting } \\
\hline Categories & $\begin{array}{c}3 \cdot 4 \\
(2 \cdot 0)\end{array}$ & $\begin{array}{c}2 \cdot 3 \\
(1 \cdot 6)\end{array}$ & $\begin{array}{c}2 \cdot 9 \\
(1 \cdot 8)\end{array}$ & $\begin{array}{l}2 \cdot 9 \\
(2 \cdot 1)\end{array}$ \\
\hline $\begin{array}{l}\% \text { Consec. persev./ } \\
\text { Total errors }\end{array}$ & $\begin{array}{c}33 \cdot 8 \\
(15 \cdot 0)\end{array}$ & $\begin{array}{c}43 \cdot 6 \\
(23 \cdot 0)\end{array}$ & $\begin{array}{l}41 \\
(24)\end{array}$ & $\begin{array}{l}42 \\
(25)\end{array}$ \\
\hline \multirow[t]{3}{*}{ Alternating verbal fluency } & & & \multicolumn{2}{|c|}{ Nerwcombe (1969) $(n=9-11)$} \\
\hline & & & LF $\quad$ LT & RF $\quad$ RT \\
\hline & $\begin{array}{c}4 \cdot 5 \\
(2 \cdot 0)\end{array}$ & $\begin{array}{c}4 \cdot 2 \\
(1 \cdot 3)\end{array}$ & $13 \cdot 3 \quad 10 \cdot 7$ & $15 \cdot 0 \quad 13 \cdot 5$ \\
\hline
\end{tabular}

$\mathrm{L}(\mathrm{R}) \mathrm{F}=$ left (right) frontal; $\mathrm{L}(\mathrm{R}) \mathrm{T}=$ left (right) temporal 


\section{Selective memory deterioration and global intellectual decline in Korsakoff patients}

Twenty-five male and 13 female Korsakoff patients (selected similarly to the males-vide supra) were examined psychometrically using the Wechsler Adult Intelligence Scale (WAIS), the Wechsler Memory Scale (WMS) and the National Adult Reading Test (NART), this last to provide an estimate of premorbid verbal intelligence. Subjects with clinical grounds for diagnosing alcoholic dementia had been excluded.

Separate indices were then calculated of: (1) Selective memory deterioration, i.e. the discrepancy between the present full scale WAIS IQ and the Wechsler memory quotient (FSIQ-WMQ); and (2) Fall in general intellectual competence, i.e. the discrepancy between present full scale WAIS IQ and the premorbid IQ estimate (NART IQ-FSIQ).

A plot of the two indices for each Korsakoff patient (Fig. 1.) shows a large amount of scatter (Jacobson and Lishman, 1987), but with no general trend for increasing memory impairment to be associated with increasing general intellectual decline (GID). Cut-off points were placed on each axis at a discrepancy level of 15 points (i.e. 1 standard deviation on the WAIS IQ and WMQ standardization samples). Twenty-four patients fall within the upper left quadrant, representing marked memory impairment but relatively slight fall in IQ; whereas 4 fall in the lower right quadrant, representing marked fall in IQ and modest memory impairment. The transition between these two extremes is gradual. The females in the sample show significantly greater impairment than the males on the index of intellectual decline.

\section{Relation of indices to CT scan findings}

Correlations of $\mathrm{C} T$ scan variables with the psychometric indices were examined in patients who had been known to suffer from AKS for less than one-and-a-half years, this cut-off point being chosen to exclude longabstinent patients, in whom psychometric performance (Parsons and Leber, 1982) and CT scan indices (Ron et al., 1982) may recover. The significant positive correlations were of IHF size and the index of GID and of sulcal width grade and the index of GID, and significant negative correlations of IHF size and the index of memory impairment (Jacobson and Lishman, 1987).

Subgroups of Korsakoff patients were assembled which showed contrasting $\mathrm{CT}$ variables (Table 5). Group $\mathrm{A}$ have wide third ventricles (i.e. exceeding the sample median) but small interhemispheric fissures (i.e. below the sample median). Group B have the reverse. Despite equivalence in age and on individual test results, Group A shows the more pronounced fall on the index of memory deterioration and Group B the more marked evidence of intellectual decline from premorbid levels.

AKS therefore appears to be heterogeneous, with patients differing in their degrees of selective memory impairment and global intellectual 


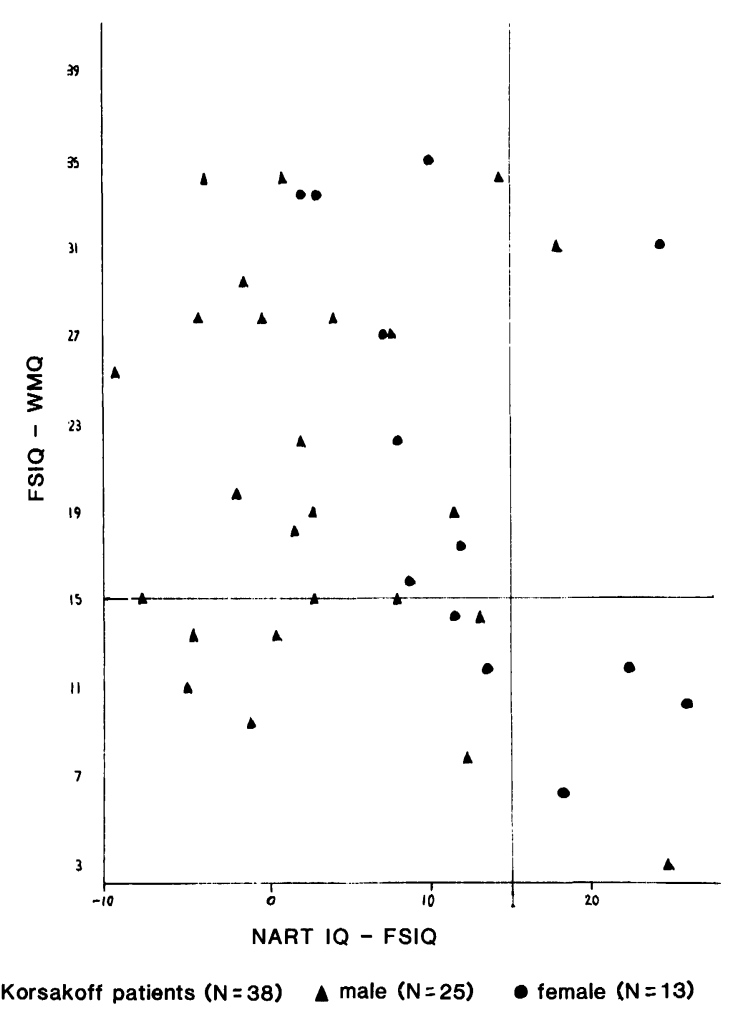

FIG. 1. Distribution of scores of Korsakoff patients $(\mathcal{N}=38)$ on the indices of selective memory loss (FSIQ-WMQ) and global intellectual decline (NART IQ-FSIQ).

TABLE 5. Comparison of mean age and mean psychometric indices in patients with large third ventricles and small interhemispheric fissures, and patients with small third ventricles and large interhemispheric fissures

\begin{tabular}{|c|c|c|c|}
\hline & $\begin{array}{c}\text { Group A Korsakoffs } \\
\text { (Large III Ventr.) } \\
\text { (Small IHF) } \\
5 M, 3 F\end{array}$ & $\begin{array}{c}\text { Group B Korsakoffs } \\
\text { (Small III Ventr.) } \\
\text { (Large IHF) } \\
3 M, 5 F\end{array}$ & $\begin{array}{l}t \text {-tests } \\
(14 d f)\end{array}$ \\
\hline Age & $56 \cdot 9$ & $56 \cdot 6$ & NS \\
\hline NART IQ & $108 \cdot 6$ & $112 \cdot 0$ & NS \\
\hline FSIQ & $105 \cdot 1$ & $98 \cdot 6$ & NS \\
\hline WMQ̄ & $79 \cdot 4$ & $81 \cdot 8$ & NS \\
\hline \multicolumn{4}{|l|}{$\begin{array}{l}\text { Index of Memory } \\
\text { Deterioration (FSIQ- }\end{array}$} \\
\hline WMQ & $25 \cdot 8$ & $16 \cdot 9$ & $p=0.06$ \\
\hline \multicolumn{4}{|l|}{$\begin{array}{l}\text { Index of Intellectual } \\
\text { Impairment (NART }\end{array}$} \\
\hline IQ-FSIQ & $3 \cdot 5$ & $13 \cdot 4$ & $p=0.05$ \\
\hline
\end{tabular}


decline, and differing also in the degrees of cortical and subcortical pathology, despite the exclusion of patients with clinical evidence of dementia. Insufficient attention has hitherto been given to the degree of GID in the disabilities of Korsakoff patients, since psychometric studies have not previously sought to chart falls in relation to estimates of premorbid competence. Extreme subgroups appear to be distinguishable from one another in measurable CT scan parameters. The heterogeneity of Korsakoff's syndrome in these regards has implications for research into its aetiological basis and treatment.

The CT scan evidence of cortical shrinkage particularly implicates frontal regions, and this accords with Harper's findings of diminished neuronal counts in the superior frontal cortex (but not in the motor cortex) of alcoholics with Wernicke's encephalopathy. The impairment in tests sensitive to frontal function and the degree of general intellectual decline both correlate significantly with inter-hemispheric fissure size, (the index of intellectual decline also showing similar trends with other cortical measures), and so must be related to alcohol neurotoxicity, not to thiamine deficiency. Thiamine deficiency is not known to impair cortical structure (Hakim and Pappius, 1981). Cortical abnormalities may therefore be important in the AKS. Their necessity in the AKS can only be fully discussed with reference to amnesic syndromes sparing the frontal lobes, e.g. the purely diencephalic and the hippocampal amnesias (see Parkin, 1984; Markowitsch and Pritzel, 1985; Squire, 1986). It is not yet clear whether the memory disorders common to AKS and frontal disorders are incidental to or necessary for Korsakoff amnesia; they are not sufficient for AKS (Mair et al., 1979; Squire, 1986).

\section{Pathophysiology}

Any account of the role of the frontal cortex in alcoholism and AKS must include recent work on neurotransmitter sources and thalamo-frontal connections. We suggest that at least three levels of pathophysiology be taken into account in any consideration of the structural and functional deficits found in alcoholic and Korsakoff patients (Fig. 2).

Cortical cell loss is found in both conditions (Harper et al., 1987). Thalamic and other diencephalic lesions, the classical hallmark of AKS, are also found in non-Korsakoff chronic alcoholics at autopsy-Harper's (1983) sub-clinical Wernicke's encephalopathy (WE); and Acker et al. (1987) have shown significant correlations of measures of recall memory and third ventricular widths in non-Korsakoff alcoholics. Cell loss in the brain stem neuro-transmitter sources has been reported most strikingly in the nucleus basalis of Meynert (NbM) in KS (Arendt et al., 1983) and in ethanol-fed rats, which developed amnesia without WE (Arendt et al., 1988). In 1984, Butters suggested that the AKS may be more accurately viewed as a cholinergic rather than a diencephalic amnesia. In 1986, Lishman attempted to explain the co-occurrence of WE pathology and alcoholic dementia by postulating that the pathological basis for a primary alcoholic 


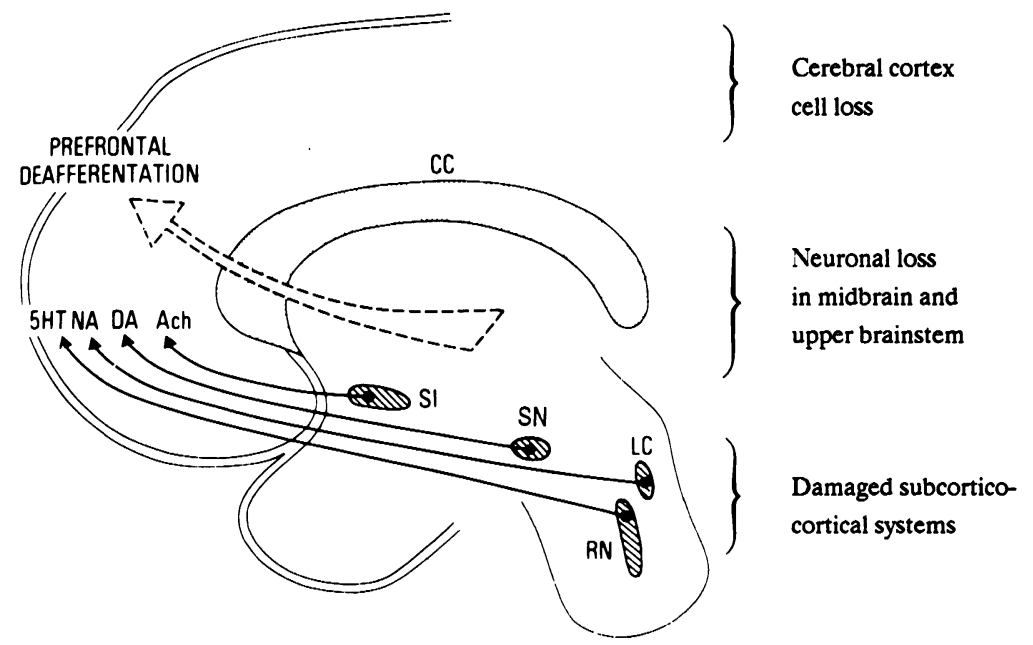

FIG. 2. Alcoholic Korsakoff's syndrome: pathological and neurochemical data suggest three levels of pathophysiology. Ach, acetylcholine; DA, dopamine; 5HT, serotonin; NA, noradrenaline; CC, corpus callosum; LC, locus coeruleus; RN, raphé nuclei; SI, substantia innominata; SN, substantia nigra.

dementia is an encroachment by an extensive WE on key forebrain nuclei concerned with cholinergic function. Recently Arendt et al. (1988), in discussing their study of ethanol-induced memory impairment in rats without WE, inferentially dismissed the diencephalon in the cholinergic and memory dysfunctions of Korsakoff patients. The precise role of Ach and of 5HT, NA and DA deficits found in both alcoholics and Korsakoffs (Freund, 1984; Witt, 1985) awaits clarification.

The subcortico-cortical neurotransmitter pathways project to the frontal lobes. The NbM projects to the ventromedial (VM) and dorsolateral (DL) prefrontal cortex (PFC) (Mesulam et al., 1983). In monkeys, lesions of VM PFC caused impaired visual recognition yet intact learning of spatial delayed responses, whereas the converse pattern followed lesions of the DL PFC (Bachevalier and Mishkin, 1986). Intact functioning of the DL PFC is also necessary for category sorting (Milner, 1964).

PET Scan studies reveal deafferentation of the frontal lobes following thalamic lesions (Bewermayer et al., 1985). Thalamo-frontal connections, by which such deafferentation may occur, have been defined using horseradish peroxidase histochemistry. The mediodorsal nucleus of the thalamus (magnocellular part) projects to orbital cortex and gyrus rectus (Goldman-Rakic and Porrino, 1985). The anteromedial nucleus of the thalamus projects to subcallosal cortex and cingulate gyrus in VM PFC (Preuss and GoldmanRakic, 1987).

An important task for future research is to clarify not only the deficits that follow selected pathology at each of these levels but also their coactions and interactions; only then will we have a detailed understanding of how the selected cognitive deficits in alcoholism and KS map onto abnormalities of frontal function and structure. 


\section{Acknowledgement}

This review is based upon work supported by a grant from the Medical Research Council.

\section{References}

Acker, W. and Acker, C. F. (1982). Bexley-Maudsley Automated Psychological Screening and BexleyMaudsley Category Sorting Test: Manual. NFER-Nelson, Windsor.

Acker, W., Ron, M. A., Lishman, W. A. and Shaw, G. K. (1984). A multivariate analysis of psychological, clinical and C'T scanning measures in detoxified chronic alcoholics. British Fournal of Addiction, 79, 293-301.

Acker, C., Jacobson, R. R. and Lishman, W. A. (1987). Memory and ventricular size in alcoholics. Psychological Medicine, 17, 343-348.

Arendt, T., Bigl, V., Arendt, A. and Tennstedt, A. (1983). Loss of neurons in the Nucleus Basalis of Meynert in Alzheimer's disease, paralysis agitans and Korsakoff's disease. Acta Neuropathologica, 61, 101-108.

Arendt, T., Allen, Y., Sinden, J., Schugens, M. M., Marchbanks, R. M., Lantos, P. L. and Gray, J. A. (1988). Cholinergic-rich brain transplants reverse alcohol-induced memory deficits. Nature, 332, 448-450.

Bachevalier, J. and Mishkin, M. (1986). Visual recognition impairment follows ventromedial but not dorsolateral prefrontal lesions in monkeys. Behavioural Brain Research, 20, 249 261.

Baldy, R. E., Brindley, G. S., Ewusi-Mensah, I., Jacobson, R. R., Reveley, M. A., Turner, S. W. and Lishman, W. A. (1986). A fully-automated computer-assisted method of CT brain scan analysis for the measurement of cerebrospinal fluid spaces and brain absorption density. Neuroradiology, 28, 109-117.

Bewermeyer, H., Dreesbach, H. A., Rackl, A., Neveling, M. and Heiss, W.-D. (1985). Presentation of bilateral thalamic infarction on CT, MRI and PET. Neuroradiology, 27, 414-419.

Butters, N. (1984). Alcoholic Korsakoff's Syndrome: an update. Seminars in Neurology, 4, 229247.

Cala, L. A., Jones, B., Mastaglia, F. L. and Wiley, B. (1978). Brain atrophy and intellectual impairment in heavy drinkers---a clinical, psychometric and computed tomography study. Australian and New Zealand Fournal of Medicine, 9, 147-153.

Claparede, E. (1911). Recognition et moiite. Archives de Psychologie, (Genève), 11, 79-90.

Cutting, J. (1978). The relationship between Korsakoff's syndrome and "Alcoholic dementia". British Fournal of Psychiatry, 132, 240-251.

de Wardener, H. E. and Lennox, B. (1947). Cerebral beri beri (Wernicke's encephalopathy). Lancet, ii, 11-17.

Freund, G. (1973). Chronic central nervous system toxicity of alcohol. Annual Review of Pharmacology, 13, 217-227.

Freund, G. (1984). Neurotransmitter function in relation to aging and alcoholism. In "Alcoholism in the Elderly" (Eds J. T. Hartford and T. Samorajski). Raven Press. New York. pp. 65-83.

Goldman-Rakic, P. S. and Porrino, L. J. (1985). The primate mediodorsal (MD) nucleus and its projection to the frontal lobe. Fournal of Comparative Neurology, 242, 535-560.

Hakim, A. M. and Pappius, H. M. (1981). The effect of thiamine deficiency on local cerebral glucose utilisation. Annals of Neurology, 9, 334-339.

Harper, C. (1983). The incidence of Wernicke's encephalopathy in Australia - a neuropathological study of 131 cases. Fournal of Neurology, Neurosurgery and Psychiatry, 46, 593-598.

Harper, C. G., Kril, T. J. and Holloway, R. L. (1985). Brain shrinkage in chronic alcoholics: a pathological study. British Medical Journal, 290, 501-504.

Harper, C., Kril, J. and Daly, J. (1987). Are we drinking our neurons away? British Medical Journal, 294, 534-536. 
Horvath, T. B. (1975). Clinical spectrum and epidemiological features of alcoholic dementia. In "Alcohol, Drugs and Brain Damage" (Ed. J. G. Rankin). Toronto, Alcoholism and Drug Addiction Research Foundation of Ontario. pp. 1-16.

Jacobson, R. R. and Lishman, W. A. (1987). Selective memory loss and global intellectual deficits in alcoholic Korsakoff's syndrome. Psychological Medicine, 17, 649-655.

Kapur, N. and Coughlan, A. K. (1980). Confabulation and frontal lobe dysfunction. Fournal of Neurology, Neurosurgery and Psychiatry, 43, 461-463.

Korsakoff, S. S. (1889). Etude Medico-psychologique sur une forme des Maladies de la Memoire. Revue Philosophique, 28, 501-530.

Lewis, A. (1952). Psychoses: alcoholic psychoses. In "British Encyclopaedia of Medical Practice", 2nd. edition. Vol. 10. Butterworth \& Co., London, pp. 394-402.

Lishman, W. A. (1981). Cerebral disorder in alcoholism. Syndromes of impairment. Brain, $104,1-20$.

Lishman, W. A. (1986). Alcoholic dementia: a hypothesis. Lancet, i, 1184-1186.

Lishman, W. A., Jacobson, R. R. and Acker, G. F. (1987). Brain damage in alcoholism: current concepts. Acta Medica Scandinavica, Suppl. 717, 5-17.

Luria, A. R. (1969). Frontal lobe syndromes. In "Handbook of Clinical Neurology", Vol. 2, (Eds P. J. Vinken and G. W. Bruyn). North Holland, Amsterdam. pp. 725-757.

Mair, W. P. G., Warrington, E. K. and Weiskrantz, L. (1979). Neuropathological and psychological examination of 2 patients with Korsakoff's psychosis. Brain, 102, 749-783.

Markowitsch, H. J. and Pritzel, M. (1985). The neuropathology of amnesia. Progress in Neurobiology, 25, 189-287.

Maudsley, H. (1879). "The Pathology of Mind", 3rd edition. Macmillan, London. p. 486.

Mesulam, M-M., Mufson, E. J., Wainer, B. H. and Levey, A. I. (1983). Central cholinergic pathways in the rat: an overview based on an alternative nomenclature (Ch 1-Ch 6). Neuroscience, 10, 1185-1201.

Milner, B. (1964). Some effects of frontal lobectomy in man. In "The Frontal Granular Cortex and Behaviour" (Eds J. M. Warren and K. Akert). McGraw Hill, New York. pp. 313-334.

Moscovitch, M. (1982). Multiple dissociations of function in amnesia. In "Human Memory and Amnesia". (Ed. L. S. Cermak). Lawrence Erlbaum Associates, Hillsdale. pp. 337370 .

Nelson, H. E. (1976). A modified card sorting test sensitive to frontal lobe defects. Cortex, 12, 313-324.

Nelson, H. E. and O'Connell, A. (1978). Dementia: the estimation of premorbid intelligence using the New Adult Reading Test. Cortex, 14, 234-244.

Newcombe, F. (1969). "Missile Wounds of the Brain", Oxford University Press.

Parkin, A. J. (1984). Amnesic syndrome: a lesion-specific disorder? Cortex, 20, 479-508.

Parsons, O. A. (1987). Intellectual impairment in alcoholics: persistent issues. Acta Medica Scandinavica Suppl. 717, 33-46.

Parsons, O. A. and Leber, W. R. (1982). Alcohol, cognitive dysfunction and brain damage. In "Alcohol and Health Monograph", No. 2. National Institute on Alcohol Abuse and Alcoholism, USGPO, pp. 213-253.

Preus, T. M. and Goldman-Rakic, P. S. (1987). Grossed corticothalamic and thalamocortical connections of macaque prefrontal cortex. Fournal of Comparative Neurology, 257, 269-281.

Robinson, A. L., Heaton, R. K., Lehman, R. A. W. and Stilson, D. W. (1980). The utility of the Wisconsin Card Sorting Test in detecting and localising frontal lobe lesions. Journal of Consulting and Clinical Psychology, 48, 605-614.

Ron, M. A., Acker, W., Shaw, G. K. and Lishman, W. A. (1982). Computerised tomography of the brain in chronic alcoholics: a survey and follow-up study. Brain, 105, 497-514.

Ron, M. A. (1983). The alcoholic brain: CT scan and psychological findings. Psychological Medicine. Monograph. Supplement 3.

Schachter, D. L., Harbluk, J. L. and McLachlan, J. (1984). Retrieval without recollection: an experimental analysis of source amnesia. Fournal of Verbal Learning and Behaviour, 23, 593-611. 
Shimamura, A. P. and Squire, L. R. (1986). Korsakoff's syndrome: a study of the relation between anterograde amnesia and remote memory impairment. Behavioural Neuroscience, $100,165 \cdots 170$.

Squire, L. R. (1982). Comparisons between forms of amnesia: some deficits are unique to Korsakoff's syndrome. Fournal of Experimental Psychology. Learning, Memory and Cognition, 8 (6), 560-571.

Squire, L. (1986). Mechanisms of memory. Science, 232, 1612-1619.

Stuss, D. T. and Benson, D. F. (1986). "The Frontal Lobes". Raven Press. New York.

Talland, G. A. (1965). "Deranged Memory-a Psychonomic Study of the Amnesic Syndrome". Academic Press, New York.

Tarter, R. E. (1973). An analysis of cognitive deficits in chronic alcoholics. Fournal of Nervous and Mental Disease, 157, 138-147.

Tarter, R. E. and Edwards, K. L. (1986). Multifactorial etiology of neuropsychological impairment in alcoholics. Alcoholism: Clinical and Experimental Research, 10, 128-135.

Torvik, A., Lindboe, C. F. and Rogde, S. (1982). Brain lesions in alcoholics. A neuropathological study with clinical correlations. Journal of Neurological Sciences, 56, 233-248.

Von Gall, M., Becker, H., Artman, H., Lerch, G. and Nemeth, N. (1978). Results of computer tomography on chronic alcoholics. Neuroradiology, 16, 329-331.

Victor, M., Adams, R. D. and Collins, G. H. (1971). "The Wernicke-Korsakoff Syndrome". Blackwell Scientific Publications, Oxford.

Weinstein, E. A. and Kahn, R. L. (1955). "Denial of Illness: Symbolic and Physiological Aspects". Charles C. Thomas, Springfield, Illinois.

Wilkinson, D. A. (1982). Examination of alcoholics by computed tomographic (CT) scans: a critical review. Alcoholism: Clinical and Experimental Research, 6, 31-45.

Witt, E. D. (1985). Neuroanatomical consequences of thiamine deficiency: a comparative analysis. Alcohol \& Alcoholism, 20, 201-221.

Zangwill, O. L. (1966). The amnesic syndrome. In "Amnesia" (Eds C. W. M. Whitty and O. L. Zangwill). Butterworths, London. pp. 77-91. 


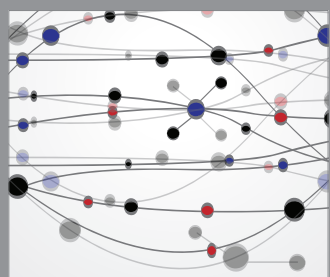

The Scientific World Journal
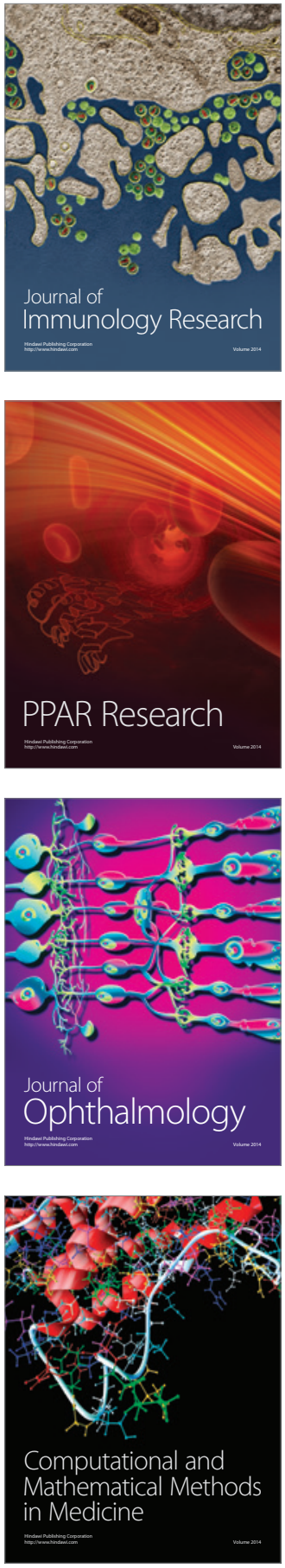

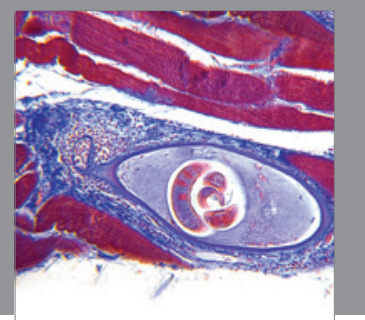

Gastroenterology

Research and Practice
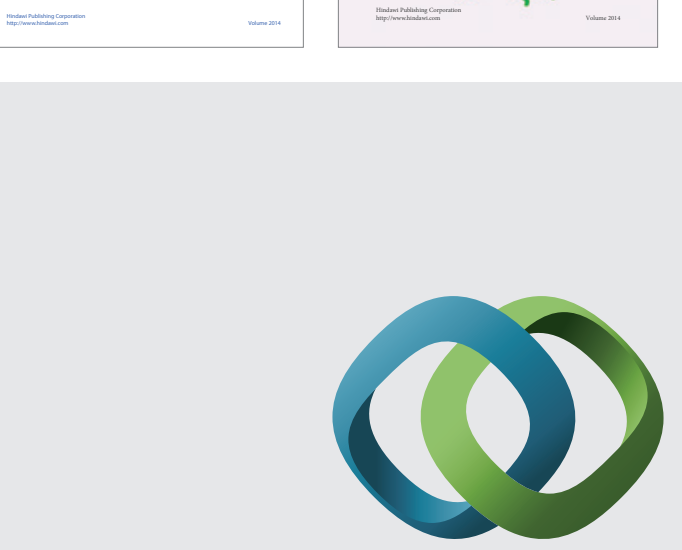

\section{Hindawi}

Submit your manuscripts at

http://www.hindawi.com
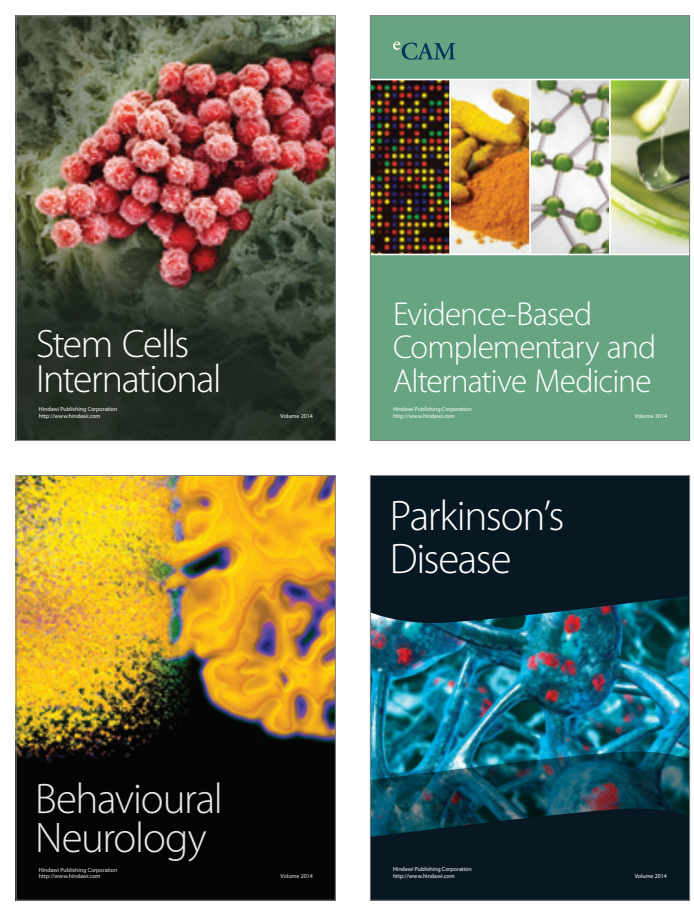

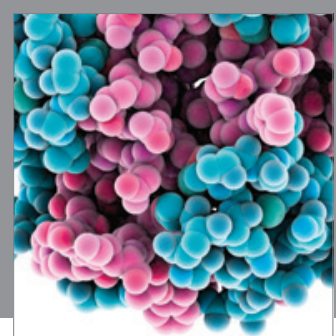

Journal of
Diabetes Research

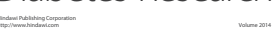

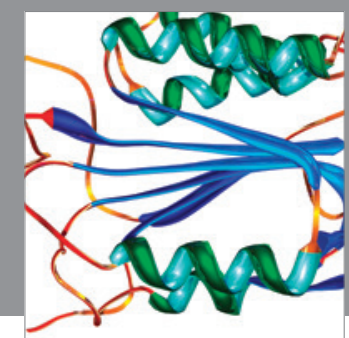

Disease Markers
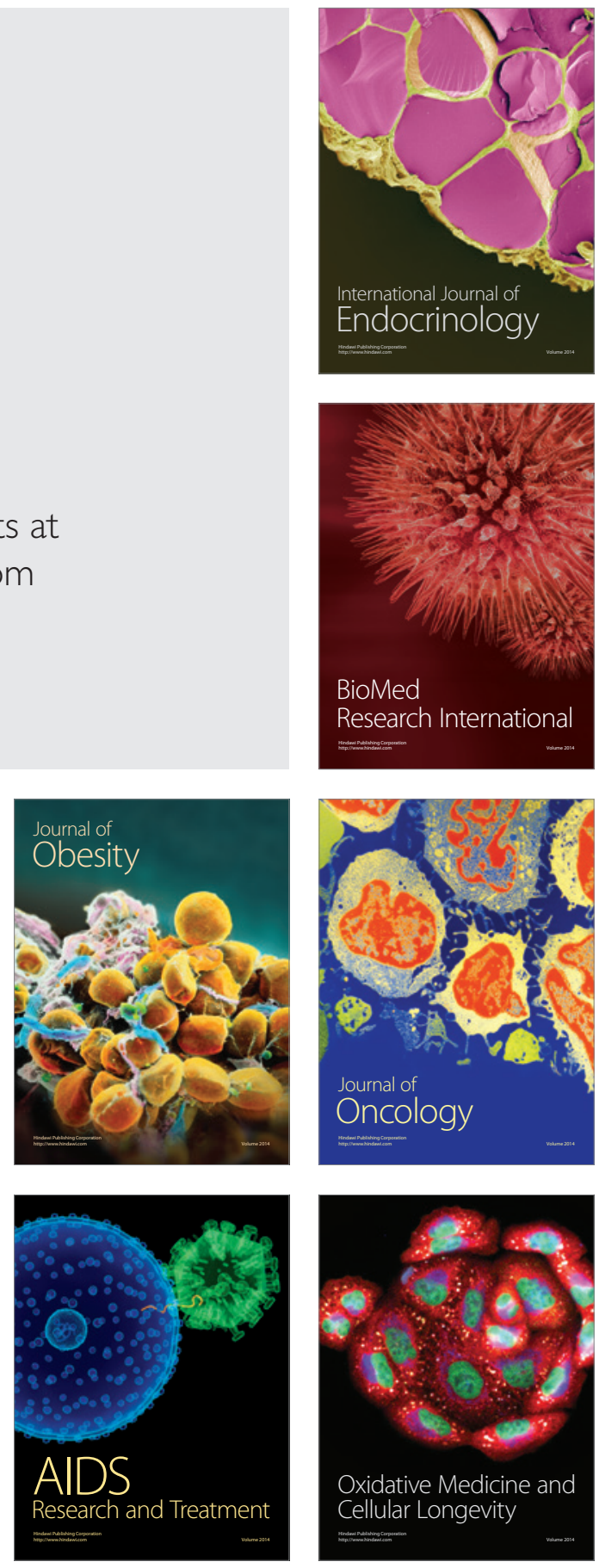